\title{
Optimization method for accurate positioning seeding based on sowing decision
}

\author{
Xueguan Zhao ${ }^{1,3}$, Liping Chen ${ }^{1,3}$, Yuanyuan Gao ${ }^{1,2,3}$, Shuo Yang ${ }^{1,2,3}$, Changyuan Zhai ${ }^{1,3^{*}}$ \\ (1. Beijing Research Center of Intelligent Equipment for Agriculture, Beijing 100097, China; \\ 2. College of Engineering, China Agricultural University, Beijing 100083, China; \\ 3. National Engineering Technology Research Center for Agricultural Intelligent Equipment, Beijing 100097, China)
}

\begin{abstract}
Variable seeding by sowing decision can improve the utilization rate of resources. In order to achieve more accurate position control and sowing rate control, precision sowing decision control system was developed, and the integral separation Proportional Integral Derivative (PID) control algorithm of metering disc speed and grid based dead reckoning method were proposed. In order to test the performance of the system, the experiment of the influence of integral switching on step response and the experiment of seeding response based on simulated sowing decision were carried out. The results showed that average lag distance based on dead reckoning was $72.2 \mathrm{~cm}$ less than that of non-dead reckoning; system response distance of integral separation PID control algorithm was $43.1 \mathrm{~cm}$ shorter than that of ordinary PID control algorithm. The field experiment showed that the error of the monitoring sowing rate relative to the actual sowing rate was $3.5 \%$, the average transition distance within the speed range of $3-9 \mathrm{~km} / \mathrm{h}$ was $139.5 \mathrm{~cm}$, and the standard deviation was $12.8 \mathrm{~cm}$. The developed seeding control system improves the accuracy of seeding based on sowing decision, and provides a technical reference for low-cost sowing decision based control system in China.
\end{abstract}

Keywords: sowing decision, positioning sowing, precision seeding control, lagging model, electric drive seed-metering DOI: $10.25165 /$ j.ijabe.20211403.5758

Citation: Zhao X G, Chen L P, Gao Y Y, Yang S, Zhai C Y. Optimization method for accurate positioning seeding based on sowing decision. Int J Agric \& Biol Eng, 2021; 14(3): 171-180.

\section{Introduction}

Accurate sowing decision is a technology that uses modern agricultural information technology to comprehensively analyze information including soil, environment, and historical yield to get detailed planting density of sowing plots and make accurate sowing. This technology combines positioning technology and variable rate application (VRA) technology for agricultural decision operations. There are many researches on variable rate fertilization ${ }^{[1,2]}$ and accurate pesticide spraying ${ }^{[3-6]}$. In recent years, more and more applications have been made in the sowing process ${ }^{[7,8]}$.

Accurate sowing requires the corn seeder to sow the seeds into the soil according to certain row spacing during the journey. Due to uneven ground, machine vibration and other reasons will affect the uniformity of seed-metering, many scholars have studied the variable control system. Through experimental research, they have explored the influence of vehicle speed ${ }^{[9,10]}$, seed filling ${ }^{[11,12]}$, vibration $^{[13]}$ and other factors on the uniformity of seed-metering, greatly improving the response speed and stability of the rotating speed of the seed-metering plate. The control system has been

Received date: $2020-02-26 \quad$ Accepted date: 2021-01-12

Biographies: Xueguan Zhao, $\mathrm{PhD}$, Associate Professor, research interests: intelligent agriculture equipment, Email: zhaoxg@nercita.org.cn; Liping Chen, $\mathrm{PhD}$, Professor, research interests: agricultural informatization and intelligent equipment technology, Email: chenlp@nercita.org.cn; Yuanyuan Gao, PhD, Lecturer, research interests: precision agriculture, Email: gaoyy0910@foxmail.com; Shuo Yang, PhD, Engineer, research interests: intelligent agricultural equipment, Email: douhj@nercita.org.cn.

*Corresponding author: Changyuan Zhai, $\mathrm{PhD}$, Professor, research interests: intelligent agriculture equipment. Beijing Research Center of Intelligent Equipment for Agriculture, Beijing 100097, China. Tel: +86-10-51503886, Email: zhaicy@ nercita.org.cn. also made many improvements, including the change from single chip microcomputer control system to electronic control unit (ECU) integrated control system, the change of system communication mode from serial port communication to controller area network (CAN) communication mode ${ }^{[9,14]}$, and the gradual development of seed-metering plate drive mode from ground wheel drive to electric drive ${ }^{[14,15]}$. The speed stability of the electric-driven seed-metering plate is directly related to the characteristics of the drive motor and the control algorithm. In the accurate sowing process based on sowing decision, large decision level difference or sudden change of driving speed will cause fluctuation or even oscillation of the motor speed ${ }^{[14]}$, affecting the effect of decision-based sowing. Therefore, good step response of motor speed $^{[16]}$ is the key to accurate sowing decision. In this article, the closed-loop control algorithm of motor speed is optimized.

Accurate sowing based on sowing decision requires not only uniformity of sowing, but also good analytical ability of the control system to the decision, i.e., small discrimination error of sowing decision. In the process of control execution, the system is affected by mechanical transmission, system inertia and global positioning system (GPS) information receiving period, and the system has certain delay. For this reason, scholars have also carried out a large number of researches. Wei et al. ${ }^{[5]}$ analyzed the reasons for the large error of prescription value in the process of variable prescription spraying through interpretation simulation tests, and quantitatively analyzed the interpretation time of prescription diagram and grid discrimination error. Chen et al. ${ }^{[6]}$ analyzed the influence of GPS positioning accuracy and period on network positioning discrimination error in prescription spraying. In order to improve the positioning accuracy, Yu et al. ${ }^{[17]}$ proposed a method of positioning variable fertilizer applicator with sensor instead of GPS, and used sensor ranging to eliminate accumulated 
error. Gao et al. ${ }^{[18]}$ adopted delay algorithm to optimize addressing to improve the implementability and accuracy of the interpretation system when designing the real-time interpretation system of unmanned aerial vehicle (UAV) variable spray prescription diagram. Li et al. ${ }^{[19]}$ used Gehash coding to design a preliminary location algorithm, which greatly improved the efficiency compared with the traditional longitude and latitude-based query. He et al. ${ }^{[20]}$ developed a sowing lag compensation algorithm, which can obtain a shorter lag distance. As can be seen from that summary of the literature, during decision-based operations, GPS positioning accuracy ${ }^{[21]}$, decision interpretation time and GPS information period are the main reasons for system time delay. At the same time, GPS positioning accuracy and grid positioning discrimination accuracy are the main reasons that affect the analytical value. GPS positioning accuracy and period can be improved by hardware, while grid positioning discrimination accuracy is not only affected by positioning accuracy but also affected by positioning identification algorithm. In order to further improve the accuracy of grid positioning discrimination, this article designs a method to correct the lag distance through the lag model.

The purpose of this article is to explore a control optimization method to reduce the speed fluctuation of the seed-metering motor caused by the large difference of sowing decision level, and propose a dead reckoning method to improve the accuracy of grid positioning discrimination, so as to improve the stability of system response and the accuracy of grid positioning discrimination.

\section{Materials and method}

\subsection{Variable sowing system based on sowing decision}

Precision variable seeder is mainly composed of seed-metering unit, tablet PC Geshem PPC-GS0792T (Shenzhen Dehang Intelligent Technology Co., Ltd., Shenzhen Guangdong, China), seed-metering drive integrated control unit ECU HYDAC-TTC32, Zhejiang AKELC AQMD3620NS-A motor driver, seed-metering motor (12 V brush DC motor), Hall speed sensor. The tablet PC is mainly used for sowing decision control operation, sending control instructions to the ECU, which is used for receiving instructions sent by the tablet PC and data from sensors, and converting sowing speed values into voltage signals through control algorithms. Voltage signal is sent to each motor driver through CANBUS, and each sowing unit motor driver receives the rotating speed data signal according to its different CAN ID number to adjust the rotating speed of the seed-metering plate. The seed-metering motor adopts brushless DC motor, and Hall sensor is installed at the shaft end to realize real-time measurement of seed-metering speed. The seeder controller supports CAN bus and ISO11783 protocol for reading, analyzing and controlling sowing decisions, and adopts closed-loop proportional-integralderivative (PID) algorithm to control the value of motor speed. The control system records the seed-metering speed and driving speed in real time and stores them in Microsoft Access database.

The variable sowing system based on sowing decision integrates GPS positioning receiver MH16-L3 (Shanghai Maihong Electronic Technology Co., Ltd., Shanghai, China) on the basis of accurate variable seeder to provide the geographical location of the system. The control interface on the tablet PC adds the functions of reading, analyzing and displaying sowing decisions. The overall design of the control system is shown in Figure 1. The basic principle of the system is to copy the operation prescription vector file based on environmental information such as soil moisture content and climate to the vehicle-mounted computer through mobile storage, and the vehicle-mounted computer displays the vector file to the electronic map according to the coordinate information of the vector file.

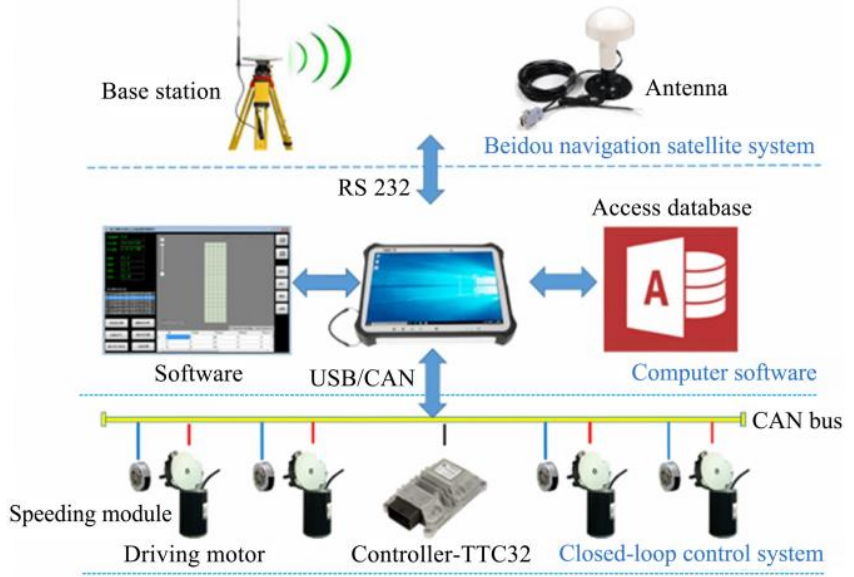

Figure 1 Composition of accurate positioning sowing system based on sowing decision

The system receives NMEA0183 format navigation message of GPS through RS232 serial port, obtains GPS positioning data in real time and analyzes planting density data at a specific position. The analyzed variables are sent to the seeder controller in the form of character strings. The seeder controller converts the planting density data into control amount, and the sowing actuator adjusts the variable sowing in real time. The variable seeder based on sowing decision is shown in Figure 2. The machine is a 4-row no tillage seeding and fertilizing integrated machine. Each row of sowing unit adopts independent drive, that is, each sowing unit is driven by a motor. The encoder is installed on the ground wheel to measure the speed. The vehicle computer is equipped with a seeding sowing -making system, which is installed in the cab, and the GPS antenna is installed on the roof.
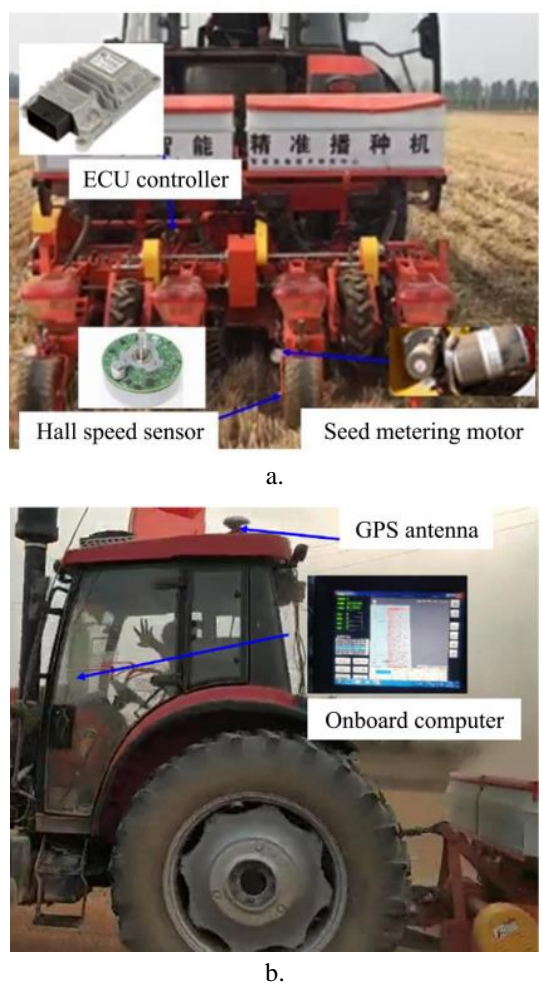

Figure 2 Composition of variable seeder based on sowing decision 


\subsection{Software design of sowing decision and control system}

The sowing decision applied in this article is provided by the cooperative organization. In order to visualize the sowing prescription data and facilitate the reading of the control system, each shape file format prescription chart file is defined: Integer field ID, floating-point field Voluml which represents sowing amount per hectare, floating-point field Volum 2 which is used to store decision coding information corresponding to field Volum1, double-precision floating-point field Long which stores longitude coordinates of prescription chart, and double-precision floating-point field Lat which stores latitude coordinates.

Based on the accurate sowing decision, the starting point is to make the seeds have the same nutrient supply. Referring to the agronomic requirements of maize sowing in Xuchang, Henan, the planting density is $57000-75000$ plants $/ \mathrm{hm}^{2}$. The decision information in the airborne control terminal uses decision codes 1-5 to represent the level of planting density, where 1 represents the lowest planting density and 5 represents the highest planting density. The sowing decision code is transmitted to the control system through universal serial bus (USB) to CAN.

After the operating position grid is recognized, the system software based on GPS positioning analyzes the sowing decision data to obtain the planting density information at the current position. According to the ISO11783 bus communication protocol, the initialization of CAN communication is realized. ECU receives the speed command issued by the controller in real time through the CAN bus and controls the speed of the seed-metering motor through PID control method to realize the variable sowing operation control function. The sowing decision workflow is shown in Figure 3.

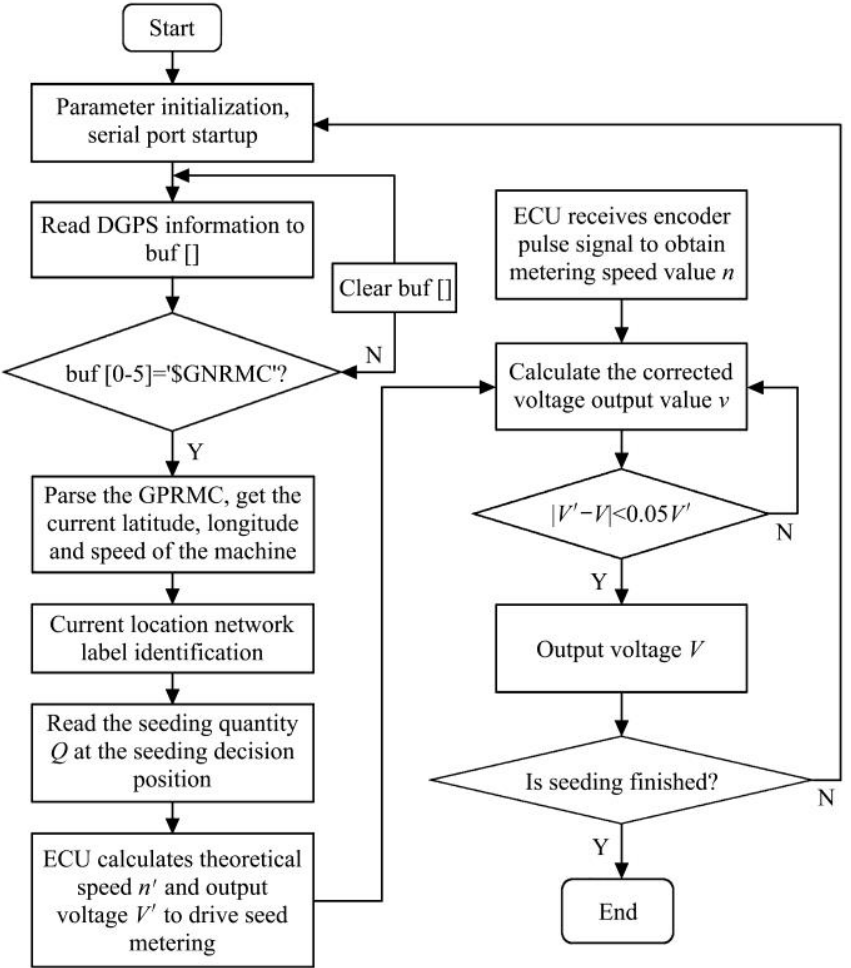

Figure 3 Work flow chart of sowing decision

As the human-computer interaction interface of the system, the control system software is developed based on VS2012 platform (Microsoft Corporation, New Mexico, USA), and is responsible for displaying and storing operating prescription diagrams and relating operating process data. C\# language is used based on Microsoft Foundation Classes (MFC) framework, and the PC human-computer interaction interface is shown in Figure 4. Figure $4 \mathrm{a}$ is the main interface of the software. It can be divided into monitoring parameters $g$ area, sowing decision display area, control display area, sowing decision value display area, system control area, sowing decision list display area. Monitoring parameters area can display the tractor speed, longitude and latitude information in real time. Sowing decision display area is used to display the current position and sowing decision in Baidu maps, and the operation trajectory is available during operation. Control display area can zoom and pan the display image. Sowing decision value area is used to display the sowing decision value read from the current point in real time. System control area is mainly used for the operation of prescription chart file, including SHP and JSON format file reading. Sowing decision list is used to read multiple files and display them in a list. After reading the prescription map file, it is marked and displayed on the map according to its coordinate position.

Figure $4 \mathrm{~b}$ is control setting interface, which mainly used for the parameter setting, display and communication debugging, which is divided into monitoring parameters area, parameter setting area, sending and receiving information display area. Parameter monitoring area is used to display the speed and rotation speed of seed metering plate. Parameter setting area is used for communication parameter setting and seeding parameter setting. Sending and receiving information display area is used to display the receiving and sending information during debugging.

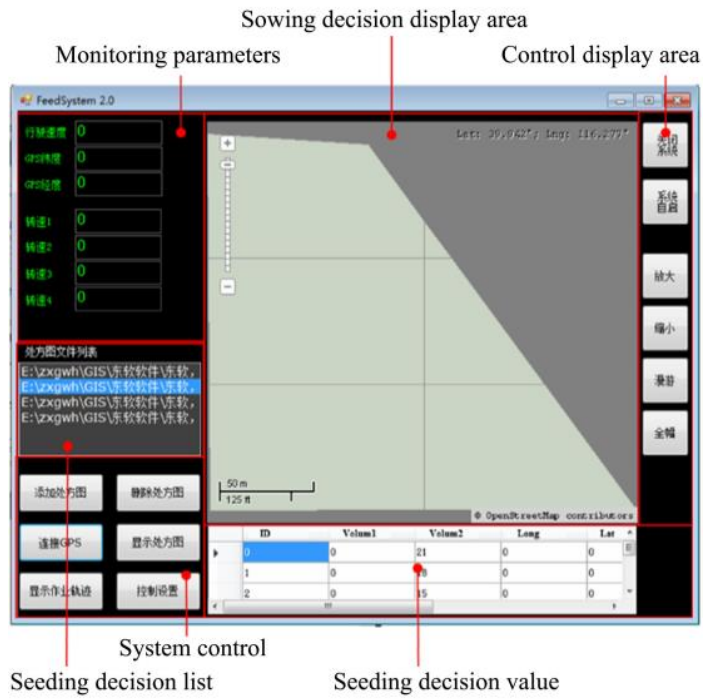

a. Main interface

Monitoring parameters Setting parameters

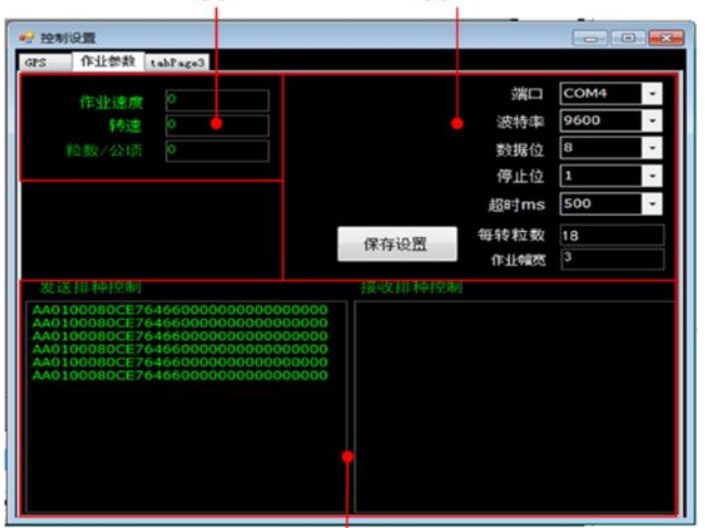

Sending and receiving information display

b. Control setting interface

Figure 4 Design of system control interface 
The embedded geographic information system software component SuperMap (Beijing Chaotu Software Co., Ltd., Beijing, China) is adopted to realize the functions of importing, editing and displaying the sowing decision diagram of vector data format (SHP) on the airborne operating control terminal. In order to obtain the target rotating speed of the seed-metering plate, the width, the number of holes in the seed-metering plate and the row spacing need to be calculated according to Equation (1).

$$
n=\frac{1000 v Q \times 4 D}{666 k \times 60}
$$

where, $n$ is the target rotating speed of the seed-metering plate, $\mathrm{r} / \mathrm{min} ; v$ is the vehicle speed, $\mathrm{km} / \mathrm{h} ; k$ is the number of holes in the seed-metering plate; $Q$ is the planting density for sowing decision, $\mathrm{kg} / \mathrm{hm}^{2} ; D$ is the row spacing, $\mathrm{cm}$.

In this study, according to the requirements of sowing row spacing, the row spacing is a fixed value of $60 \mathrm{~cm}$, the number of holes in the selected seed-metering plate is 18 , and the vehicle speed is $3-9 \mathrm{~km} / \mathrm{h}$. The control software calculates the target rotating speed of the current seed-metering plate in real time according to the analyzed current vehicle speed and planting density.

\subsection{Optimization of location delay model and decision recognition algorithm}

The current coordinates obtained by GPS positioning system are taken as the coordinate values of the sowing decision, and the coordinate values are taken as the theoretical target seed falling position. In fact, due to the layout of the hardware system, the spatial position is shifted, and the relative distance between the target position and the actual seed falling position is shown in Figure 5.

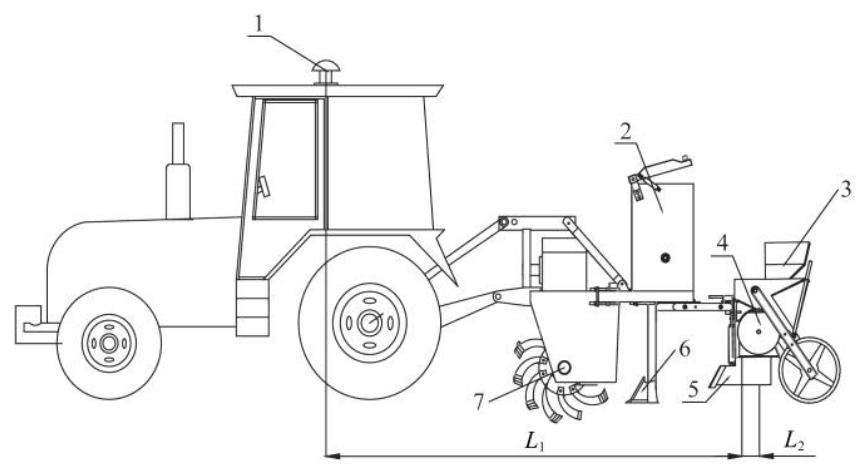

1. GPS receiving antenna 2. Fertilizer box 3. Seed box 4. Seed-metering device 5. Sowing ditching shovel 6 . Fertilizing shovel 7. Stubble breaking mechanism

\section{Figure 5 Sowing lag diagram}

Relative distance mainly includes the distance $L_{1}(\mathrm{~cm})$ of the GPS antenna relative to the seed-metering port, the distance $L_{2}(\mathrm{~cm})$ of the seed falling from the seed-metering port and moving in the horizontal direction, showing as follows:

$$
L=L_{1}+L_{2}
$$

where, $L$ is lag distance, $\mathrm{cm} ; L_{2}$ can be calculated from the seed-metering process of the picker finger seed drill, $\mathrm{m}$. The system has a certain response time from obtaining the sowing position to the seed falling, which can be expressed as:

$$
T=t_{1}+t_{2}+t_{3}+t_{4}
$$

where, $T$ is System response time, $\mathrm{s} ; t_{1}$ is time for GPS positioning analysis, $s ; t_{2}$ is the acceptance time when the control terminal sends an instruction to the controller, $\mathrm{s} ; t_{3}$ is the response time of the driver and the seed-metering motor, $\mathrm{s} ; t_{4}$ is the time when seeds fall to the ground from the seed-metering opening, $s$.
The lag distance $\Delta d$ of the sowing position is

$$
\Delta d=L-T \cdot V_{t}
$$

where, $\Delta d$ is lag distance, $\mathrm{m} ; V_{t}$ is traval speed, $\mathrm{m} / \mathrm{s}$.

In order to achieve the purpose of accurate positioning and sowing, the lag distance model is used as the adjustment basis for airborne control terminals. The accurate sowing system based on sowing decision control is implemented according to the decision quantity of operating grid. The position of the machines and tools provided by GPS in the sowing decision is an important factor affecting the target fertilization amount, but GPS has poor dynamic response capability. In order to further improve the accuracy of grid position analysis in the sowing decision process, a dead reckoning based on velocity sensor was carried out. Encoders E38S6G5-100B-G5N (OMRON Corporation, Kyoto, Japan) with a resolution of 500 pulses per turn. The A-phase pulses of the encoder are received through TTC32 controller's frequency count $\mathrm{I} / \mathrm{O}$ port. The ground wheel velocity $V_{t}(\mathrm{~m} / \mathrm{s})$ can be expressed as

$$
V_{t}=\frac{2 \pi f r \times 3.6}{n}
$$

where, $n$ is the number of pulses per revolution of the limited-depth wheel; $r$ is the radius of the limited-depth wheel, $\mathrm{m} ; f$ is the pulse frequency value recorded at a certain time, $\mathrm{Hz}$; A coordinate system $x O y$ is established for the plot. The $x$ axis of the coordinate system is parallel to the latitude line and the $y$ axis is parallel to the longitude line. If the rotation of the $x O y$ coordinate makes the $\mathrm{x}$ axis parallel to the boundary of the working plot, the geodetic coordinate value obtained by the receiver can be converted into the longitude and latitude coordinate value in the $x^{\prime} O y^{\prime}$ space rectangular coordinate according to Equation (6).

$$
\left\{\begin{array}{l}
x^{\prime}=x \cos \alpha+y \sin \alpha \\
y^{\prime}=-x \sin \alpha+y \cos \alpha
\end{array}\right.
$$

where, $x$ and $\mathrm{y}$ are the longitude and latitude coordinate values measured by the receiver, $\mathrm{m}$, and $x^{\prime}$ and $y^{\prime}$ are the longitude and latitude coordinate values in the $x^{\prime} O y^{\prime}$ coordinate system, m. $\alpha$ is the included angle between the two coordinate systems, ${ }^{\circ}$.

The machine travels at a certain speed, and the heading angle is obtained by GPS analysis. At this time, the sowing decision value is analyzed by dead reckoning. As shown in Figure 6, there is a large difference in the level of sowing decision levels from grid $\mathrm{A}$ and grid $\mathrm{B}$ to grid $\mathrm{C}$. At the sampling point $\mathrm{P}_{0}$ identified after entering grid $\mathrm{B}$ during the tractor driving process, the coordinates of $P_{t}$ are calculated through the relative relationship between the sampling point and the lag distance $\Delta d$ as follows.

$$
\left\{\begin{array}{l}
p_{\text {tlng }}=p_{0 l n g}+\frac{180 \Delta d}{\pi R \cos \operatorname{lng}} \cos \beta \cdot \cos \alpha \\
p_{\text {tlat }}=p_{0 l a t}+\frac{180 \Delta d}{\pi R} \cos \beta \cdot \sin \alpha
\end{array}\right.
$$

where, $p_{\text {thng }}$ is the longitude of the calculated $x^{\prime} O y^{\prime}$ coordinate system, $\mathrm{m} ; p_{\text {tlat }}$ is the latitude of the calculated $x^{\prime} O y^{\prime}$ coordinate system, $\mathrm{m} ; p_{0 \text { lng }}$ is $P_{0}$ longitude; $p_{\text {0lat }}$ is $P_{0}$ latitude; lng is the longitude value of the current operation position, $\mathrm{m} ; R$ is the radius of the earth, the path of the plot is a straight line, $\mathrm{m} ; \beta$ is $0^{\circ}$ or $180^{\circ}$ for the heading angle of the machine and tool in the space rectangular coordinate system, ${ }^{\circ}$.

In order to eliminate the influence of lag distance on sowing, the region to which the calculated coordinates belong was determined according to the dead reckoning coordinates, and the grid analysis was carried out in advance. 




Figure 6 Relation between dead reckoning and hysteresis

\subsection{Optimization method of sowing speed control}

The response characteristic of the working speed of the seed-metering plate is one of the key factors for the sowing system to realize accurate positioning and sowing. In order to improve the accuracy of the control of the seed-metering plate, PID closed-loop control algorithm was adopted in this article. However, when the tractor accelerates or decelerates in the field during the sowing process, the planting density decision will increase or decrease sharply. The output of the seed-metering motor has a large deviation in a short period of time, which will cause integral accumulation of PID operation and overshoot or oscillation. Therefore, the corresponding start-up jump values were calculated by fitting equations under different velocity gradients respectively ${ }^{[15]}$. This article introduces an integral separation algorithm into PID algorithm, that is, when the deviation value is large, the integral effect is cancelled to avoid the increase of overshoot, while when the deviation value is small, the integral effect is introduced to eliminate static error and improve control accuracy. The control algorithm can be expressed as:

$$
U(k)=K_{\mathrm{p}} \operatorname{err}(k)+\beta k_{i} \sum_{j=0}^{k} \operatorname{err}(j)+k_{d}(\operatorname{err}(k)-\operatorname{err}(k-1))
$$

where, $U(k)$ is the corresponding adjustment value at the $k$ th sampling; $k_{p}$ is the proportional coefficient; $k_{i}$ is the integral coefficient; $k_{d}$ is the differential coefficient; $\operatorname{err}(k)$ is the calculation deviation; $\beta$ is called the integral switching coefficient, and its value range is:

$$
\beta=\left\{\begin{array}{l}
1|\operatorname{err}(k)| \leq \varepsilon \\
0|\operatorname{err}(k)|>\varepsilon
\end{array}\right.
$$

where, $\varepsilon$ is the change threshold of the set speed and the actual speed. In this study, the monitoring of the sowing speed is used as feedback. $\varepsilon$ represents the setting threshold value of the difference between the measured speed and the target speed. From the above equation, it can be seen that the selection of $\varepsilon$ value is difficult to realize. If $\varepsilon$ value is too large, the effect of integral separation cannot be achieved, while if $\varepsilon$ value is too small, it is difficult to enter the integral area. Therefore, the $\varepsilon$ value needs to be determined.

\subsection{Test design}

\subsubsection{Determination of $\varepsilon$ value}

$\varepsilon$ value needs to be set according to specific objects and requirements; otherwise, the control effect of integral separation cannot be achieved and the control accuracy is affected. Firstly, PID parameters were adjusted several times when the speed difference was small. The proportional coefficient $k_{p}$, integral coefficient $k_{i}$ and differential coefficient $k_{d}$ of the closed-loop system were determined to be $0.155,0.35$ and 0.07 , respectively. Then, the speed step response was carried out by setting the sowing decision level, and the integral switching coefficient was determined. During the test, the theoretical rotating speed $n(t)$ $(\mathrm{r} / \mathrm{min})$ of the motor was calculated by setting the planting density (57 000-75000 plants/ $/ \mathrm{hm}^{2}$ ) of the controller and maintaining the vehicle speed at $6 \mathrm{~km} / \mathrm{h}$ during operation. The target rotating speed $N^{\prime}(t)(\mathrm{r} / \mathrm{min})$ of the seed-metering plate was calculated by the product of the theoretical rotating speed and the reduction ratio. The seeder controller obtains the feedback rotating speed $N(t)$ $(\mathrm{r} / \mathrm{min})$ by monitoring the drive motor shaft through the encoder. In this article, 18 holes were selected, the row spacing was $60 \mathrm{~cm}$, and the calculated rotating speed range of the seed-metering plate was $9.5-37.6 \mathrm{r} / \mathrm{min}$. Range of rotation is $0-38 \mathrm{r} / \mathrm{min}$. Start from $10 \mathrm{r} / \mathrm{min}$, and increase the speed by $4 \mathrm{r} / \mathrm{min}$ in each test until it reaches to $34 \mathrm{r} / \mathrm{min}$. The value was determined by monitoring the output analog quantity change of the controller. Finally, the speed step test of 0-38 r/min was carried out on the integral separation control algorithm added with the integral switching. The feedback speed value was monitored and recorded by CAN data analyzer to investigate the performance of integral separation PID control.

2.5.2 Field experiments simulating sowing decisions

In order to test the performance of the system, a test area was selected. The test area was located in Wanzhuang Village $\left(125^{\circ} 30^{\prime} \mathrm{E}, 44^{\circ} 96^{\prime} \mathrm{N}\right)$, Chencao Town, Xuchang City, Henan Province, the main corn producing area in China. Xianyu 335 corn seeds were selected for the test.

In order to investigate the influence of dead reckoning algorithm and integral separation algorithm on sowing, a simulated sowing decision experiment was carried out. Figure 7 is the distribution diagram and division of the experimental field. The experimental field covers an area of $57.6 \mathrm{~m} \times 60 \mathrm{~m}$. Three groups were set up. The first group is no dead reckoning area and ordinary PID control area (NDR-PID, abbreviated as NDP), the second group is dead reckoning area and ordinary PID control area (Dr \& PID, abbreviated as DP), and the third group is no dead reckoning area and integral separation PID (NDr \& ISPID, abbreviated as NDIP). Each group set the planting density $Q$ as 0-66000-0-57000-66000-75000 plants/ $\mathrm{hm}^{2}$ (sowing decision level $0-3-0-1-3-5)$, each decision level is $10 \mathrm{~m}$ and is represented by different colors as shown in Figure 7a.

During the test, the unit traveled at a constant speed of 3, 6 and $9 \mathrm{~km} / \mathrm{h}$ along each operation zone, and the on-board computer recorded the latest decision analysis time and the currently executing planting density prescription value in real time. The encoder installed on the drive shaft of the seed-metering plate fed back the frequency signal, and used the frequency divider to output two frequency signals, one as the speed feedback of ECU and the other as the monitoring signal. At the same time, the system automatically recorded the coordinates of the current operation.

After four experiments, each group had 16 crop rows. Five rows were randomly selected by manual seed picking to collect data respectively. 15 plant spacings were continuously measured in each row to pick out all the seeds. All the test data were recorded in the form of seed spacing $d$. If the error between the seed distance and the target seed distance is less than $10 \%$, it is regarded as reaching the target seed distance. As shown in Figure 8a, in the deceleration process, under the condition of $75000 \mathrm{plants} / \mathrm{hm}^{2}$, the target plant spacing is $22.2 \mathrm{~cm}$, the measured value is 23.4 , and the error is less than $10 \%$. But when the plant spacing is 17.3 , it is considered that the target seed spacing is not reached. The distance from the boundary of the decision level area to reaching the target particle distance is defined as lag distance $(L D)$.

$$
M L D=(L D 1+L D 2+L D 3+L D 4+L D 5) / 5
$$

where, $L D 1, L D 2, L D 3$ and $L D 4$ are the lag distances of 5 rows respectively, $\mathrm{cm} ; M L D$ is the average of the lag distances of this 5 rows, $\mathrm{cm}$. 
According to Figure $8 \mathrm{~b}-\mathrm{c}$, when the sowing decision changes from 1 to 3 (57 000 seeds $/ \mathrm{hm}^{2}$ to 66000 seeds $/ \mathrm{hm}^{2}$ ), it is difficult to observe the change of grain distance directly according to the

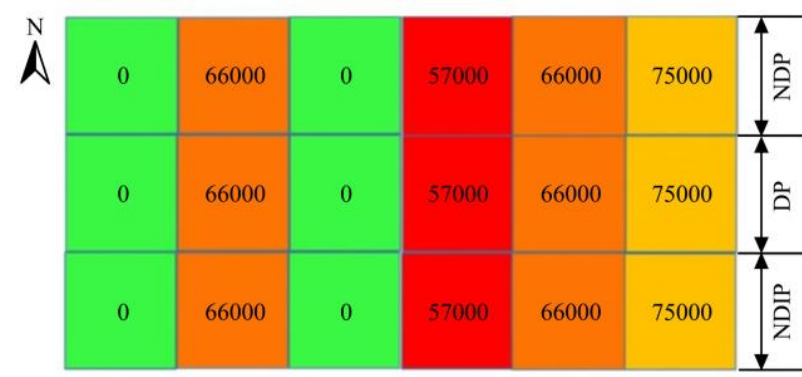

$1: 1608$

a. Control group area design

measured data. Therefore, the measured data are input to Matllab 2012 software to draw the grain distance change curve, and the lag of grain distance is determined through the change of the curve.

Note: Green represents planting density is 0 plants $/ \mathrm{hm}^{2}$; orange represents planting density is 66000 plants/hm ${ }^{2}$; straw yellow represents planting density is 75000 plants $/ \mathrm{hm}^{2}$; red represents planting density is 57000 plants $/ \mathrm{hm}^{2}$. NDP is no dead reckoning and ordinary PID control area; DP is dead reckoning and ordinary PID control area; NDIP is no dead reckoning and integral separation PID area.

Figure 7 Plot division for simulated sowing decision test

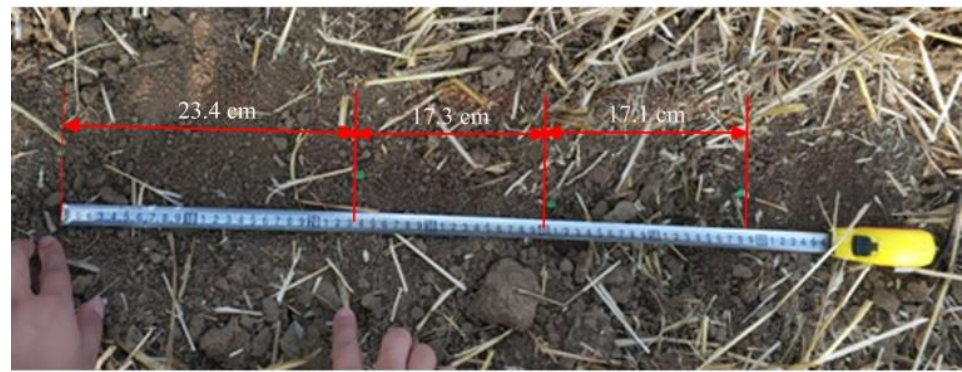

a. Measured boundary of different sowing decision levels

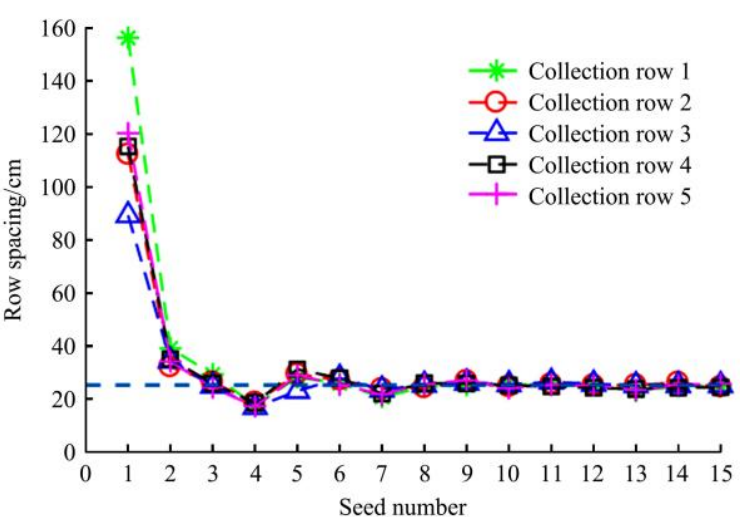

b. Change of particle spacing without dead reckoning when the seeding decision level changes from 1 to 3

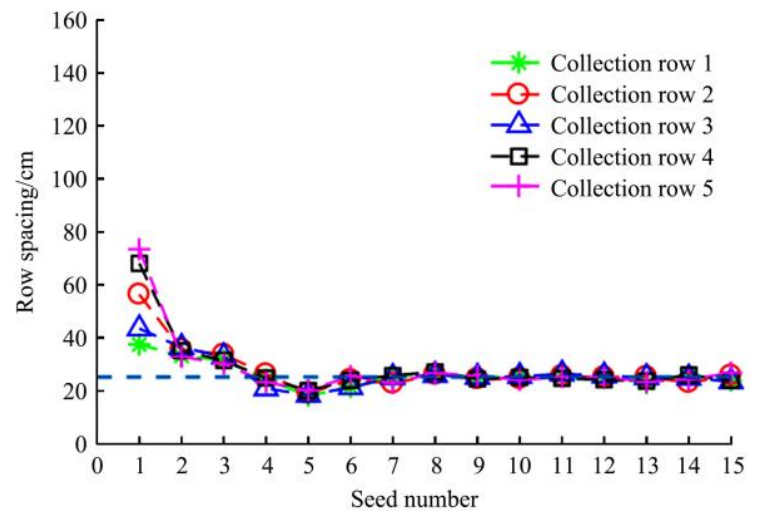

c. Change of particle spacing with dead reckoning when the sowing decision level changes from 1 to 3

Figure 8 Comparison of seed spacing change with and without dead reckoning

\subsubsection{Field trials of actual sowing decisions}

According to the soil and environmental information, the sowing decision reference is formulated according to the agronomic model, as shown in Figure 9. During the test, the sowing parameters under different vehicle speeds were recorded in the corresponding plot area of the decision reference, and the actual sowing performance based on the sowing decision was investigated.

In the actual sowing process, the zoning operation was carried out according to the target speed of 3, 5, 7 and $9 \mathrm{~km} / \mathrm{h}$ respectively. Through the above-mentioned data recording method, the recorded data was input to ArcGis 10.4.1 to draw the actual vehicle speed distribution map and the motor monitoring speed map, and then the monitoring broadcast quantity distribution map was drawn. The actual plant spacing of each decision code area and boundary was measured by hand-held GPS. Data processing and evaluation were based on the national standard of China, Test Method for Single Grain (Precision) Seeder (GB/T 6973-2005), and the qualified index of grain distance and coefficient of variation were taken as indexes to evaluate the performance of the control system.

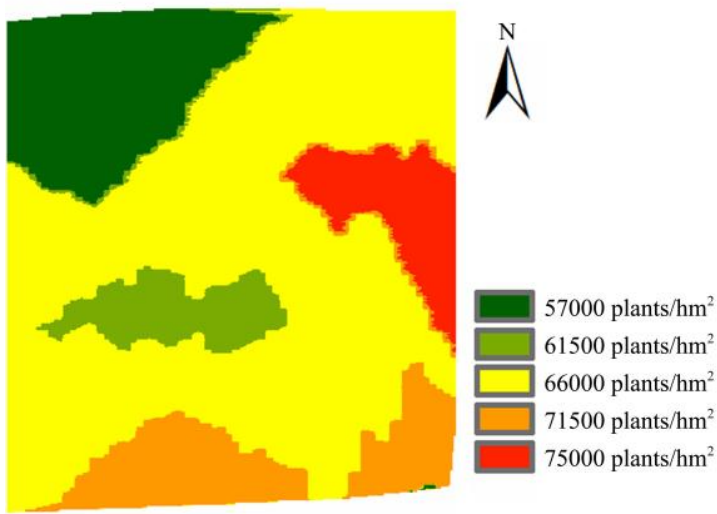

Note: different colors represent different planting density.

Figure 9 Sowing decision reference 


\section{Results and Discussion}

\subsection{Influence of integral term on step response}

The statistics of controller voltage output for speed steps of 4 , 16 and 24 r/min are shown in Figure 10.

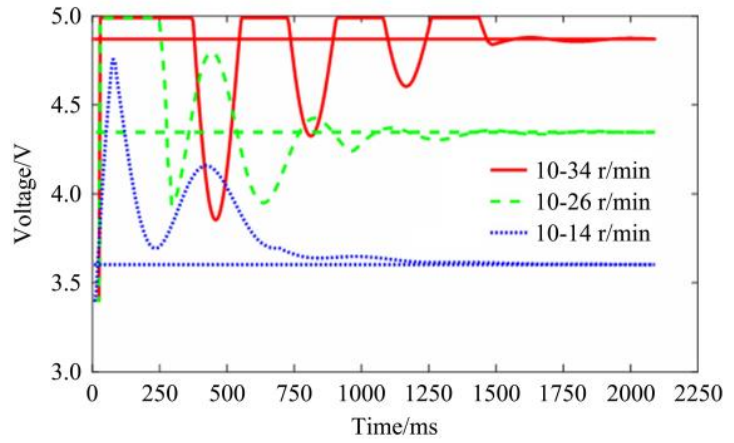

Figure 10 Variation of drive voltage of controller with integral term

According to the output voltage change waveform of the controller, during the rotating speed change process of 10-14 r/min, the voltage fluctuation steps from $3.4 \mathrm{~V}$ to the maximum value of $4.75 \mathrm{~V}$, and the voltage tends to stable state within $1.2 \mathrm{~s}$. During the speed step of 10-26 r/min, the voltage steps from $3.4 \mathrm{~V}$ to $5 \mathrm{~V}$ and tends to be stable within $1.4 \mathrm{~s}$. During the speed step of 10-34 $\mathrm{r} / \mathrm{min}$, the voltage steps from $3.4 \mathrm{~V}$ to $5 \mathrm{~V}$, and the voltage oscillates to the peak value of $5 \mathrm{~V}$ many times, which is an important factor causing system instability. Through statistics of different speed steps, it is found that when the speed step is more than $18 \mathrm{r} / \mathrm{min}$, it is the critical point for the integral term to cause oscillation. The results of speed step test at $0-38 \mathrm{r} / \mathrm{min}$ are as Figure 11.

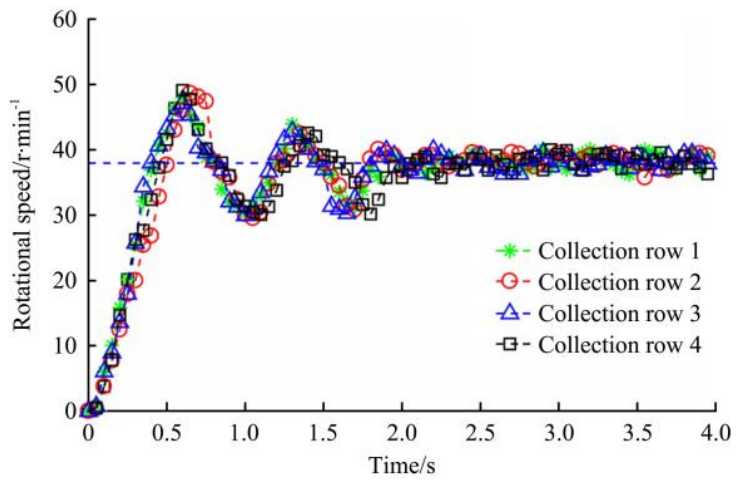

a. Ordinary PID

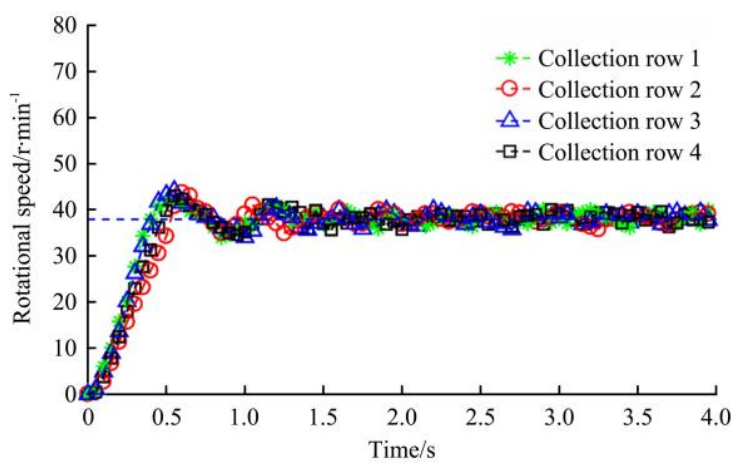

b. Integral Separation PID

Figure 11 Monitoring rotational speed of seed-metering plate

The improved system (Figure 11b) takes $1.3 \mathrm{~s}$ time from issuing operation instructions to stabilizing the seed-metering motor, which reduces $0.7 \mathrm{~s}$ and has a faster response. At the same time, the overshoot of seed-metering speed is reduced. The overshoot of ordinary PID seed-metering speed is $28.9 \%$, whereas the overshoot of integral separation PID is $10.5 \%$, thus reducing the instantaneous impact on the seed-metering plate and improving the stability.

3.2 System response test based on simulated sowing decision

3.2.1 Influence of dead reckoning on sowing lag distance

Statistics were made on the lag distance under different speeds and decision levels. Lag distance between NDP area and NDIP area was compared. The results are shown in Figure 12.

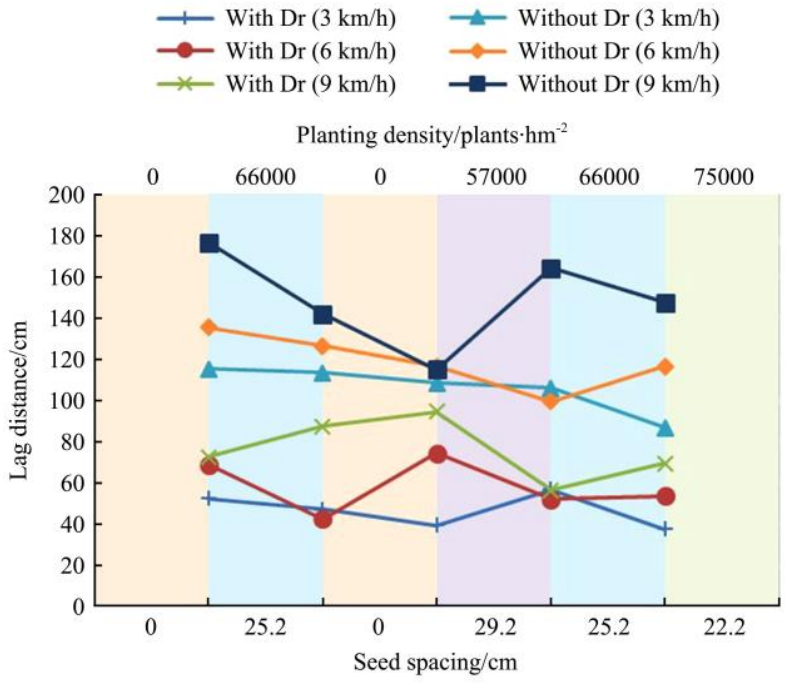

Note: Dr is dead reckoning

Figure 12 Comparison of lag distance between dead reckoning and no dead reckoning under different speeds and decision levels

As can be seen from Figure 12, the overall lag distance of no dead reckoning is significantly higher than that with dead reckoning algorithm. The overall average lag distance based on dead reckoning is $63.4 \mathrm{~cm}$, while that of no dead reckoning is $135.6 \mathrm{~cm}$, which shows that dead reckoning reduces the lag distance by $72.2 \mathrm{~cm}$. The lag distance basically shows a trend of increasing with the increase of vehicle speed, which indicates that the higher the vehicle speed, the farther the distance the system travels in the response period. At the same time, the fluctuation of lag distance with dead reckoning algorithm is smaller than that of no dead reckoning, which shows that dead reckoning can effectively reduce the influence of GPS acceptance period and velocity sampling interval on lag distance. This conclusion is consistent with the research by $\mathrm{Li}$ et $\mathrm{al}^{[19]}$. Comparing the lag distance between decision level 0 to 3 and 3 to 0 , it is found that there is no obvious rule between the lag distance and sowing decision level, which indicates that decision level has no effect on the lag distance.

3.2.2 Influence of integral separation PID on sowing response

The application of integral separation PID algorithm is proposed to avoid the oscillation of the control system when the rotating speed difference of the seed-metering plate is large. The rotating speed of the system changes when the sowing decision level changes. The response distance is determined by the response time from the beginning of response to the entry of the stable state. The response distance results of NDP area and NDIP area are shown in Figure 13.

As can be seen from Figure 13, when the sowing decision level changes in the range of $0-3-0-1$, the system average response distance with the integral separation PID control algorithm is $71.2 \mathrm{~cm}$, whereas that with the ordinary PID control algorithm is 
$114.3 \mathrm{~cm}$, which shows that the integral separation PID algorithm reduces the response distance by $43.1 \mathrm{~cm}$. The response distance of PID control system using integral separation is obviously lower than that of ordinary PID control system when the decision level changes in the range of level 0-3-0. When the sowing decision level is small (1-3-5), taking the vehicle speed of $6 \mathrm{~km} / \mathrm{h}$ as example, the change of the sowing speed is $19-22-25 \mathrm{r} / \mathrm{min}$, and the change of the speed is small. According to the above values, the test shows that the response distance under different travel speed has no obvious difference between with and without integration term, which is consistent with the results shown in the Figure 13. Comparing the response distance of under sowing decision level of 0-3-0 with that under sowing decision level of 1-3-5, it can be seen that the greater the sowing decision level changes, the more obvious the effect of integral separation PID on shortening the response distance of the system. The greater the sowing decision level changes, the more obvious the effect of vehicle speed on shortening the response distance of the system, which is due to the double influence of vehicle speed and sowing decision level on the sowing speed.

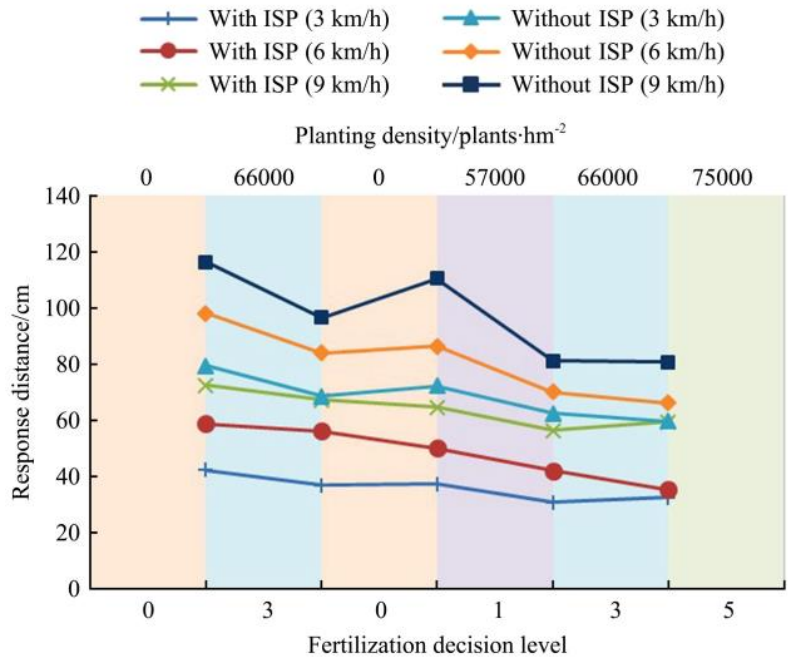

Figure 13 Comparison of response distances between integral separation algorithm and non-integral separation algorithm under different speeds and decision levels

\subsection{System performance test based on actual sowing decision}

The rotating speed of the seed-metering plate is affected by the travel speed and the sowing decision level. In order to better display different rotating speeds, 9 intervals were drawn for the rotating speed. According to the monitoring data of vehicle speed and seed-metering plate speed, the distribution map was drawn on the operation plot as shown in Figure 14, where the seed-metering plate speed is the average value of the four-way seed-metering device speed.
According to the distribution diagram of vehicle speed, it can be seen that the vehicle speed in different speed regions fluctuates in a certain extent when operating according to the target speed. According to the statistics of monitoring values, it is found that the target vehicle speed fluctuates most in the area of $9 \mathrm{~km} / \mathrm{h}$, with an average vehicle speed of $9.2 \mathrm{~km} / \mathrm{h}$ and a variance of $0.54(\mathrm{~km} / \mathrm{h})^{2}$, which meets the needs of vehicle speed control. Figure $14 \mathrm{~b}$ shows that the rotational speed of the seed-metering plate is correlated with the vehicle speed. The rotational speed of the seed-metering plate is affected by the decision levels, and there is a phenomenon of fluctuation in some areas. For example, in the black border area with the target vehicle speed of $5 \mathrm{~km} / \mathrm{h}$, the vehicle speed distribution is uniform but the rotating speed fluctuates from 18.2 to $25.9 \mathrm{r} / \mathrm{min}$. The main reason is that there are more stubble in the area and the uneven surface causes the vibration of the sowing unit, thus affecting the uniformity of rotating speed. The maximum monitoring speed for the target speed areas of 3, 5, 7 and $9 \mathrm{~km} / \mathrm{h}$ are 3.4, 5.3, 7.6 and $8.8 \mathrm{~km} / \mathrm{h}$ respectively. The corresponding theoretical rotational speed and monitoring rotational speed are shown in Table 1.
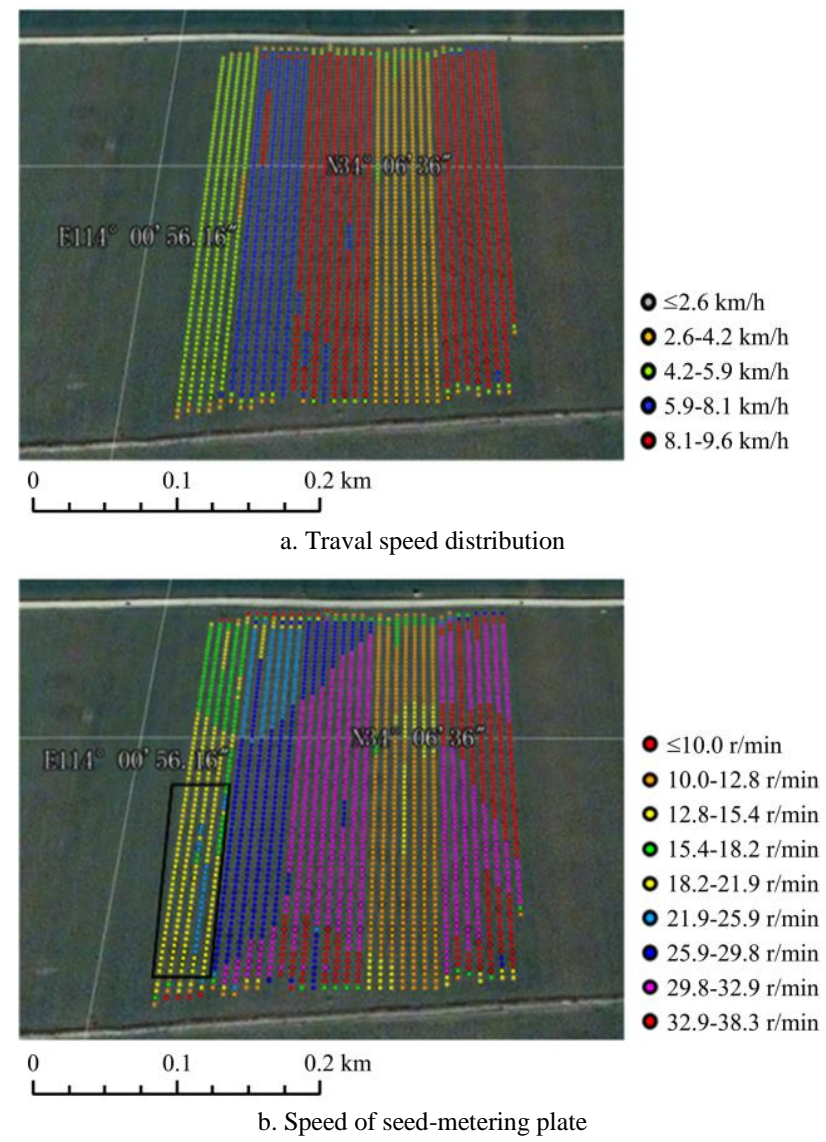

Figure 14 Distribution of monitoring data

Table 1 Comparison of actual speed and theoretical speed of seed metering motor under different traval speeds

\begin{tabular}{|c|c|c|c|c|c|c|c|c|c|c|c|}
\hline \multirow{3}{*}{$\begin{array}{l}\text { Vehicle } \\
\text { speed } \\
/ \mathrm{km} \cdot \mathrm{h}^{-1}\end{array}$} & \multicolumn{10}{|c|}{ Rotational speed of each sowing decision level/r $\cdot \min ^{-1}$} & \multirow{3}{*}{$\begin{array}{c}\text { Average } \\
\text { relative error } \\
\text { rate } / \%\end{array}$} \\
\hline & \multicolumn{2}{|r|}{1} & \multicolumn{2}{|r|}{2} & \multicolumn{2}{|r|}{3} & \multicolumn{2}{|r|}{4} & \multicolumn{2}{|r|}{5} & \\
\hline & Theory & Monitoring & Theory & Monitoring & Theory & Monitoring & Theory & Monitoring & Theory & Monitoring & \\
\hline 3.4 & 10.77 & 11.11 & 11. 61 & 11.23 & 12.45 & 12.73 & 13.30 & 13.52 & 14.12 & 14.59 & 2.7 \\
\hline 5.3 & 16.39 & 17.24 & 18.40 & 18.61 & 19.31 & 19.73 & 20.33 & 21.29 & -- & -- & 3.2 \\
\hline 8.8 & -- & -- & 30.05 & 29.13 & 32.22 & 30.69 & 33.62 & 32.49 & 36.75 & 34.80 & 4.3 \\
\hline
\end{tabular}


As can be seen from Table 1, with the increase of vehicle speed, the relative error between the theoretical rotational speed and the monitoring rotational speed of the seed-metering plate increases continuously. Namely, with the increase of sowing decision, this difference is gradually obvious, which is determined by the working characteristics of the seeder. The higher the sowing decision level, the greater the planting density. At the same time, the higher the rotating speed of the seed-metering plate when encountering resistance changes, the greater the fluctuation. According to the monitoring data of sowing situation in each sowing decision level area and under different operation speeds, the distribution of sowing quantity monitoring data is drawn as Figure 15. The actual monitoring distribution of sowing quantity is in a very good consistency with sowing decision. According to the statistics of monitored planting density in each sowing decision level area, the average error of monitored planting density relative to actual planting density is $3.5 \%$.

Actual measurement and statistics were carried out on the grain spacing after actual sowing. Because the difference of actual decision-making level is 2, according to the above analysis, the influence of level difference can be ignored. The variation trend of lag distance and response distance with the change of vehicle speed is shown in Figure 16. It can be seen

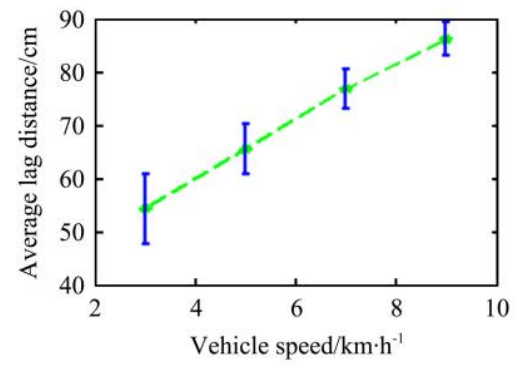

the speed has a significant influence on lag distance and response distance. The standard deviation of the lag distance gradually decreases with the increase of the vehicle speed, mainly due to the unstable feedback of the vehicle speed obtained through the vehicle speed sensor at low speed. The sum of lag distance and response distance is considered as the transition distance when the sowing decision level changes, which can be used as an index to reflect the overall performance of the system. The average transition distance is $139.5 \mathrm{~cm}$ and the standard deviation is $12.8 \mathrm{~cm}$.

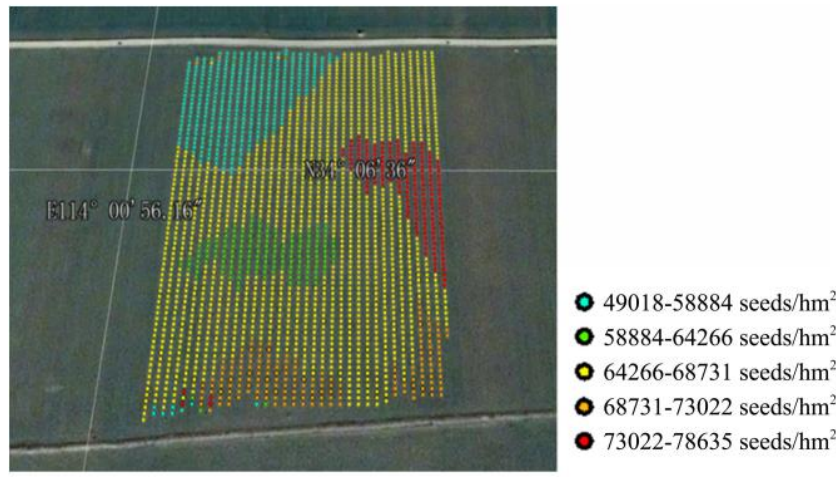

Figure 15 Distribution of monitoring seed-metering quantity

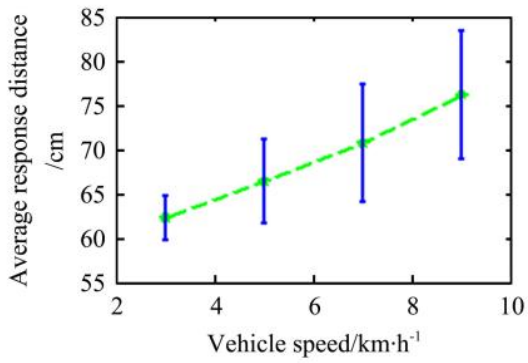

Figure 16 Variation trend of (a) lag distance and (b) response distance with vehicle speed

\section{Conclusions}

The variable control system based on CAN bus was built, and the variable control system interface based on sowing decision was developed to realize reading and analysis of sowing decision. A position lag model was established, and a dead reckoning algorithm based on Hall sensor real-time speed measurement and an integral separation PID control algorithm for seed plate speed were proposed. The experiment of the influence of integral term on step response determined that the rotating speed threshold with or without integral term was $18 \mathrm{r} / \mathrm{min}$. The integral separation control method reduced the system response by $0.7 \mathrm{~s}$, and at the same time reduced the phenomenon of seed-metering rotating speed overshoot from $28.9 \%$ to $10.5 \%$, reducing the instantaneous impact on the seed-metering plate and improving the stability. The experiment based on simulated sowing decision showed that the average lag distance based on dead reckoning was $63.4 \mathrm{~cm}$, which was $72.2 \mathrm{~cm}$ less than that based on no dead reckoning. The system response distance of integral separation PID control algorithm was $71.2 \mathrm{~cm}$, which was $43.1 \mathrm{~cm}$ less than that of ordinary PID control algorithm. The experiment based on the actual sowing decision showed that the error between the monitored planting density and the actual planting density was 3.5\%, the average transition distance in the vehicle speed range of 3-9 km/h was $139.5 \mathrm{~cm}$, and the standard deviation was $12.8 \mathrm{~cm}$.

\section{Acknowledgements}

This study was financially supported by the National Key Research and Development Program (Grant No. 2017YFD0700502).

\section{[References]}

[1] Meng Z J, Zhao C J, Fu W Q, Ji Y X, Wu G W. Prescription map identification and position lag calibration method for variable rate application of fertilizer. Transactions of the CSAM, 2011; 7: 204-209. (in Chinese)

[2] Xie Y W, Yang J Y, Du S L, Zhao J, Li Y, Huffman E C. A GIS-based fertilizer decision support system for farmers in Northeast China: a case study at Tong-le village. Nutrient Cycling in Agroecosystems, 2012; 93: 323-336

[3] Xu X, Zhang H, Xi L, Ma X M, Wang J C. Decision-making system for wheat precision fertilization based on WebGIS. Transactions of the CSAE 2011; 27(Supp.2): 94-98. (in Chinese)

[4] Yin D F, Chen S R, Pei W C, Shen B G. Design of map-based indoor variable weed spraying system. Transactions of the CSAE, 2011, 27(4): 131-135. (in Chinese)

[5] Wei X H, Dan Z M, Sun H W, Zhang J M. Development of vehicular embedded information processing system for map-based precision farming. Transactions of the CSAE, 2013; 29(6): 142-149. (in Chinese)

[6] Chen Z G, Chen M X, Wei X H, Li J Y, Li L. Variable prescription pesticide spraying system for farmland based on the Beidou Navigation Satellite Syste. Journal of Drainage and Irrigation Machinery Engineering (JDIME), 2015; 33( 11): 965-970. (in Chinese)

[7] Ehsani M R, Durairaj C D, Woods S, Sullivan M. Potential application of 
electrical conductivity (EC) map for variable rate seeding. Agricultural Engineering International: the CIGR journal, 2005; 7: 1-17.

[8] He X T, Ding Y Q, Zhang D X, Yang L, Cui T, Zhong X J. Development of a variable-rate seeding control system for corn planters Part I: Design and laboratory experiment. Computers and Electronics in Agriculture, 2019; 162: 318-327.

[9] Yang S, Wang X, Gao Y Y, Zhao X G, Dou H J, Zhao C J. Design and experiment of motor driving bus control system for corn vacuum seed meter. Transactions of the CSAM, 2019; 50(2): 57-67. (in Chinese)

[10] Ding Y Q, Yang L, Zhang D X, Cui T, He X T, Zhong X J. Control system of motor-driving maize precision planter based on GPS speed measurement. Transactions of the CSAM, 2018; 49(8): 42-49. (in Chinese)

[11] Shi S, Zhang D X, Yang L, Cui T, Li K H, Yin X W. Simulation and verification of seed-filling performance of pneumatic-combined holes maize precision seed-metering device based on EDEM. Transactions of the CSAE, 2015; 31(3): 62-69. (in Chinese)

[12] Ding L, Yang L, Liu S R, Yan B X, He X T, Zhang D X. Design of air suction high speed precision maize seed metering device with assistant seed filling plate. Transactions of the CSAE, 2018; 34(22): 1-11. (in Chinese)

[13] Zhai C Y, John L, Taylor R, Weckler P, Wang N. Field scale row unit vibration affecting planting quality. Precision Agriculture, 2019; 1-14.

[14] He X T, Ding Y Q, Zhang D X, Yang L, Cui T, Wei J T, et al. Design and evaluation of PID electronic control system for seed meters for maize precision planting. Transactions of the CSAE, 2017; 33(17): 28-33. (in
Chinese)

[15] Ding Y Q, Yang L, Zhang D X, Cui T, Zhang K L, Wang M T. Design of row-unit driver for maize variable rate planter. Transactions of the CSAE, 2019; 35(11): 1-9. (in Chinese)

[16] Shamshiri R, Ismail W I W. Design and simulation of control systems for a field survey mobile robot platform. Research Journal of Applied Sciences, 2013; 6(13): 2307-2315.

[17] Yu Y J, Zhang S H, Qi J T, Zhang L h. Positioning method of variable rate fertilizer applicator based on sensors. Transactions of the CSAE, 2009; 40(10): 165-168. (in Chinese)

[18] Gao R T, Shan J, Yang Z, Wen S, Lan Y B, Zhang Q Y, et al. Real-time interpretation system of variable spray prescription map based on plant protection UAV. Journal of Jilin University, 2020; 50(1): 361-374. (in Chinese)

[19] Li R, Ding Y, Yu H F, Du Y Y, You J, Shi H X, et al. Construction and application of the electronic prescription map system of variable rate fertilization in Southern Jiangsu. Journal of China Agricultural University, 2017; 22(8): 124-132. (in Chinese)

[20] He X T, Ding Y Q, Zhang D X, Cui L Y, T, Zhong X J. Development of a variable-rate seeding control system for corn planters Part II: Field performance. Computers and Electronics in Agriculture, 2019; 162: 309-317.

[21] Shamshiri R, Ismail W I W. Exploring GPS data for operational analysis of farm machinery. Research Journal of Applied Sciences, 2013; 5(12): 3281-3286. 